\title{
Synthesis of Enantiomerically Enriched
}

\section{Oxazolinyl[1,2]Oxazetidines}

\author{
Renzo Luisi, Vito Capriati, Saverio Florio* and Eliana Piccolo
}

Dipartimento Farmaco-Chimico, Università di Bari, Via E. Orabona 4, I-70126 - Bari, C.N.R.,

Istituto di Chimica dei Composti OrganoMetallici "ICCOM", Sezione di Bari, Italy.

E-mail:florio@farmchim.uniba.it

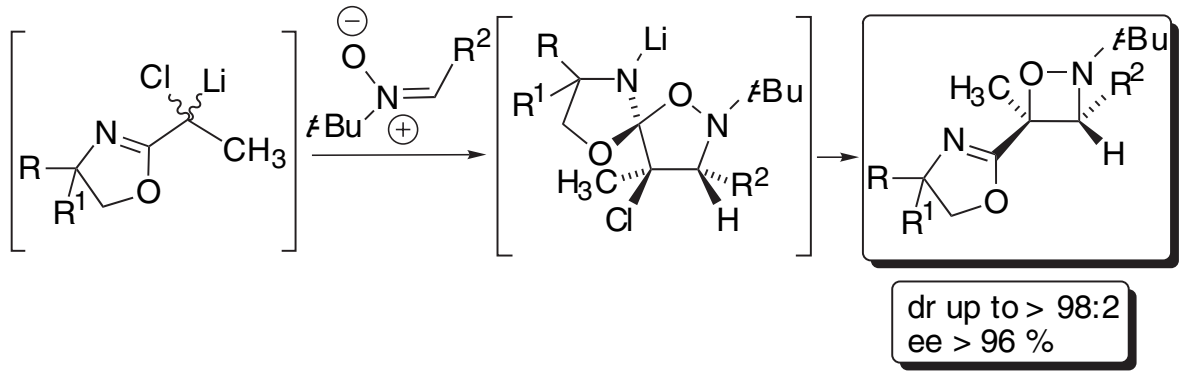




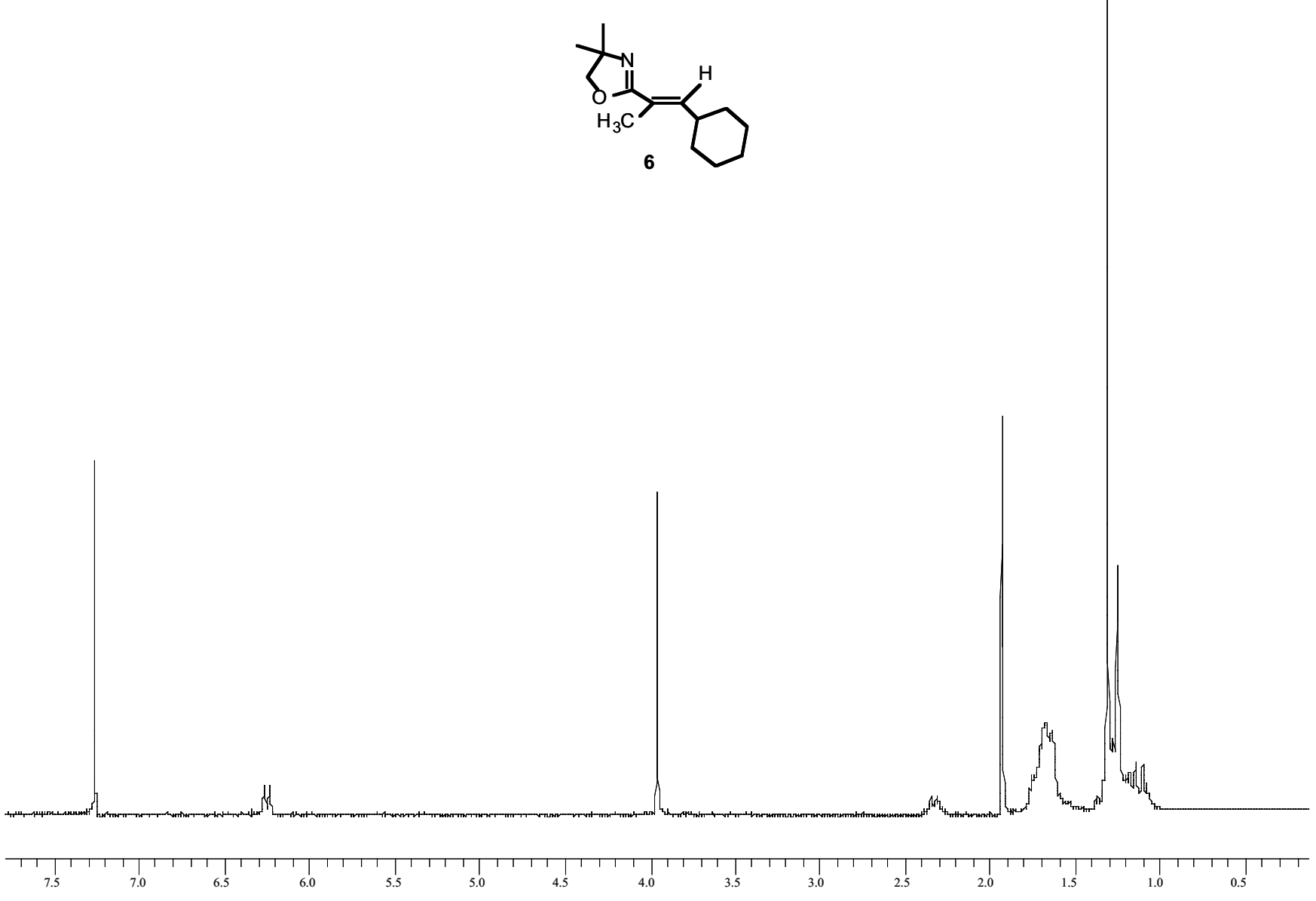

Figure S1

SI 


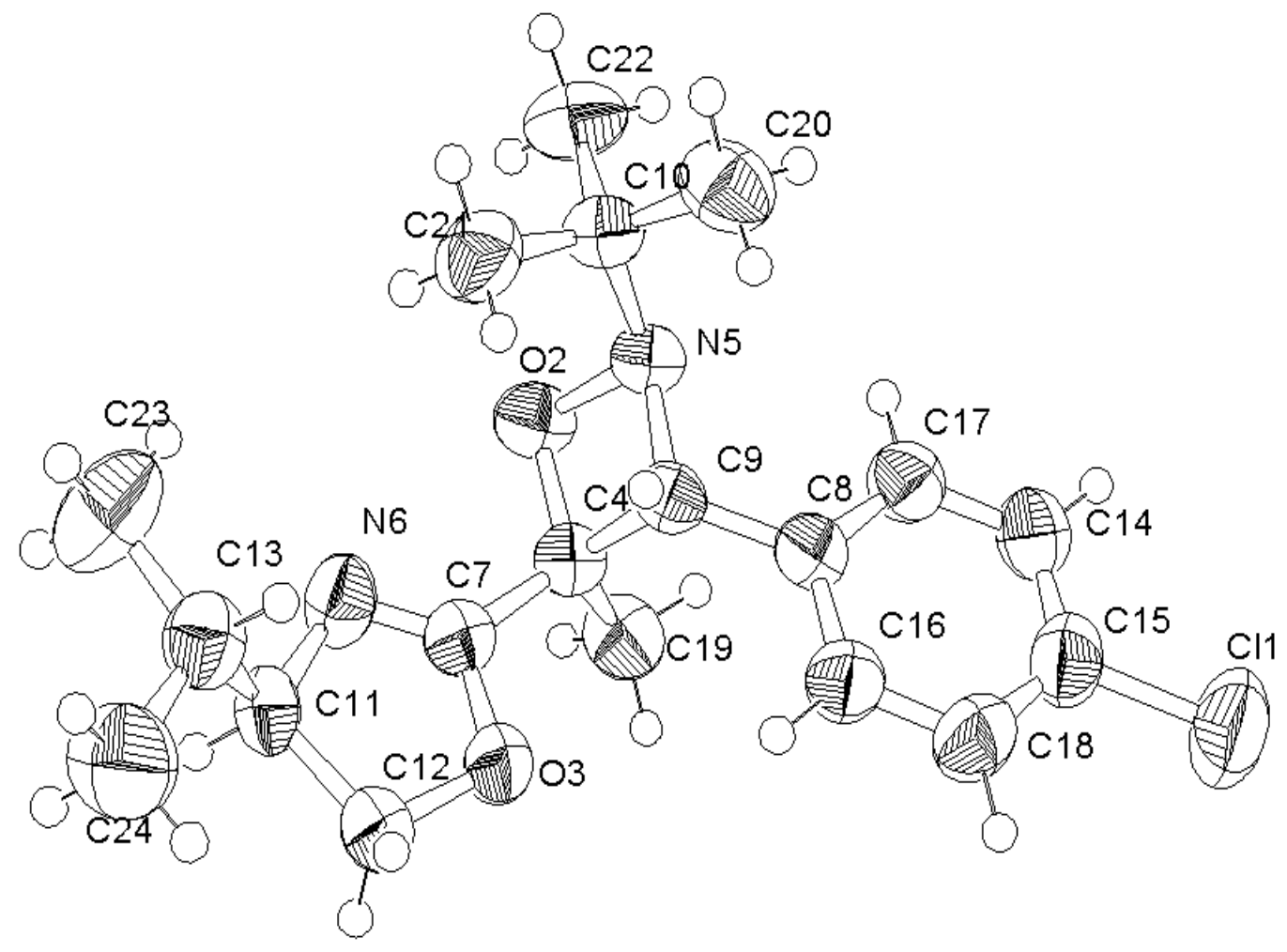

Figure S2. ORTEP view of oxazolinyl[1,2] oxazetidine (-)-10c. 